\title{
Engineering of a high lipid producing Yarrowia lipolytica strain
}

\author{
Jonathan Friedlander', Vasiliki Tsakraklides' ${ }^{1}$ Annapurna Kamineni², Emily H. Greenhagen², \\ Andrew L. Consiglio ${ }^{2}$, Kyle MacEwen², Donald V. Crabtree ${ }^{2}$, Jonathan Afshar ${ }^{2}$, Rebecca L. Nugent ${ }^{1,4}$, \\ Maureen A. Hamilton², A. Joe Shaw ${ }^{2}$, Colin R. South ${ }^{2}$, Gregory Stephanopoulos ${ }^{2,3}$ and Elena E. Brevnova ${ }^{1,5^{*}}$
}

\begin{abstract}
Background: Microbial lipids are produced by many oleaginous organisms including the well-characterized yeast Yarrowia lipolytica, which can be engineered for increased lipid yield by up-regulation of the lipid biosynthetic pathway and down-regulation or deletion of competing pathways.
\end{abstract}

Results: We describe a strain engineering strategy centered on diacylglycerol acyltransferase (DGA) gene overexpression that applied combinatorial screening of overexpression and deletion genetic targets to construct a high lipid producing yeast biocatalyst. The resulting strain, NS432, combines overexpression of a heterologous DGA1 enzyme from Rhodosporidium toruloides, a heterlogous DGA2 enzyme from Claviceps purpurea, and deletion of the native TGL3 lipase regulator. These three genetic modifications, selected for their effect on lipid production, enabled a $77 \%$ lipid content and $0.21 \mathrm{~g}$ lipid per g glucose yield in batch fermentation. In fed-batch glucose fermentation NS432 produced $85 \mathrm{~g} / \mathrm{L}$ lipid at a productivity of $0.73 \mathrm{~g} / \mathrm{L} / \mathrm{h}$.

Conclusions: The yields, productivities, and titers reported in this study may further support the applied goal of costeffective, large -scale microbial lipid production for use as biofuels and biochemicals.

Keywords: Yarrowia lipolytica, Lipid accumulation, Oleaginous yeast, Metabolic engineering

\section{Background}

Microbial lipid production has received applied interest both for the synthesis of specialty chemicals and for the production of fuels and bulk chemicals from low-cost carbon feedstocks [1]. Considering the high demand for lipid molecules, augmentation of current plant- and animal-based production by microbial conversion of starch and sugar crops, agricultural residues, and lignocellulosic material has been the subject of many recent studies. Among natively oleaginous organisms, which are capable of producing lipids at a level greater than $20 \%$ of their dry cell weight, the well-characterized yeast Yarrowia lipolytica [2] has received particular interest. Wild-type $Y$. lipolytica can accumulate lipids up to $36 \%$ of dry cell weight from glucose [3] and 50-60\% of dry cell weight

\footnotetext{
*Correspondence: contact@novogyinc.com

${ }^{1}$ Total New Energies, 5858 Horton Street, Emeryville, CA 94610, USA Full list of author information is available at the end of the article
}

when fed exogenous fatty acid substrates for biomodification to higher value fats and oils $[4,5]$, and researchers have metabolically engineered strains to produce high value lipids [6-8]. In addition to production and biomodification of lipids, $Y$. lipolytica strains are capable of secreting low-molecular weight secondary metabolites such as citric acid and polyols, and extracellular enzymes under specific fermentation conditions $[9,10]$. Extensive genetic systems have been developed to manipulate this yeast $[9,11,12]$.

Lipids serve as energy storage molecules and building blocks for cellular membranes and are composed of fatty acids, isoprenoids, and other water-insoluble hydrocarbon molecules. In many oleaginous yeasts, fatty acids are the dominant lipid compound, constituting 90-95\% of total lipid material $[13,14]$. To avoid the potentially toxic and membrane-disturbing effects of free fatty acids, they are incorporated into nonpolar lipids such as triacylglycerols (TAG) and sterol esters. TAGs are stored in 
subcellular compartments termed lipid droplets or lipid bodies [15-18].

Several applied studies have focused on increasing TAG production through genetic engineering of TAG synthesis and degradation pathways [19-21], including recent publications that have pushed previous limits of $Y$. lipolytica lipid productivity and titer [22-24]. A series of proteins were postulated as regulators of the conversion of carbohydrate sources into TAGs: malic enzyme (ME), ATP citrate lyase (ACL), Acetyl-CoA carboxylase (ACC), Bifunctional glycerol-3-phosphate/glycerone-phosphate O-acyltransferase (SCT), 1-acylglycerol-3-phosphate O-acyltransferase (SLC1), Stearoyl-CoA desaturase (SCD), and phospholipid: diacylglycerol Acyltransferase (LRO) (Fig. 1).

In particular, the enzymes DGA1 (diacylglycerol acyltransferase type 2) and DGA2 (diacylglycerol acyltransferase type 1) have been recognized as key components of the lipid pathway, performing the final step of TAG synthesis, incorporation of the third acyl-CoA onto the diacylglycerol backbone and transport into the lipid droplet [23]. Up-regulation of the native $Y$. lipolytica DGA1 and DGA2 enzymes have significantly increased lipid yield and productivity $[19,21,26]$, and it has been hypothesized that efficient diacylglycerol acyltransferase activity creates a critical driving force for high levels of lipid accumulation in oleaginous organisms due to its dual role in TAG biosynthesis and transport into the lipid droplet $[19,27,28]$. Additionally, it has been shown that the deletion of DGA2 impairs TAG synthesis and lipid production in Y. lipolytica [25]. It has also been demonstrated that DGA1 or DGA2 overexpression is beneficial for lipid accumulation in $R$. toruloides [29] as well as in plant seeds [30].

In this study, we describe a systematic lipid biosynthesis engineering approach centered on diacylglycerol acyltransferase gene overexpression. First, we evaluated combinations of endogenous gene targets and then we optimized key enzymes by screening heterologous genes for engineering of an improved lipid-accumulating biocatalyst. The resulting strain of this process reached a $77 \%$ lipid content and a 0.21 g lipid per g glucose yield in batch glucose fermentation, while in fed-batch glucose fermentation it produced $85 \mathrm{~g} / \mathrm{L}$ lipid at a $0.73 \mathrm{~g} / \mathrm{L} / \mathrm{h}$ productivity.

\section{Results/discussion}

Overexpression of endogenous DGA1 in Yarrowia lipolytica In an effort to develop a biocatalyst for industrial lipid production, we evaluated several $Y$. lipolytica wild-type strains for desirable biocatalyst qualities, such as minimal citric acid secretion, non-hyphal morphology, and ease of genetic manipulation. We isolated one such strain,

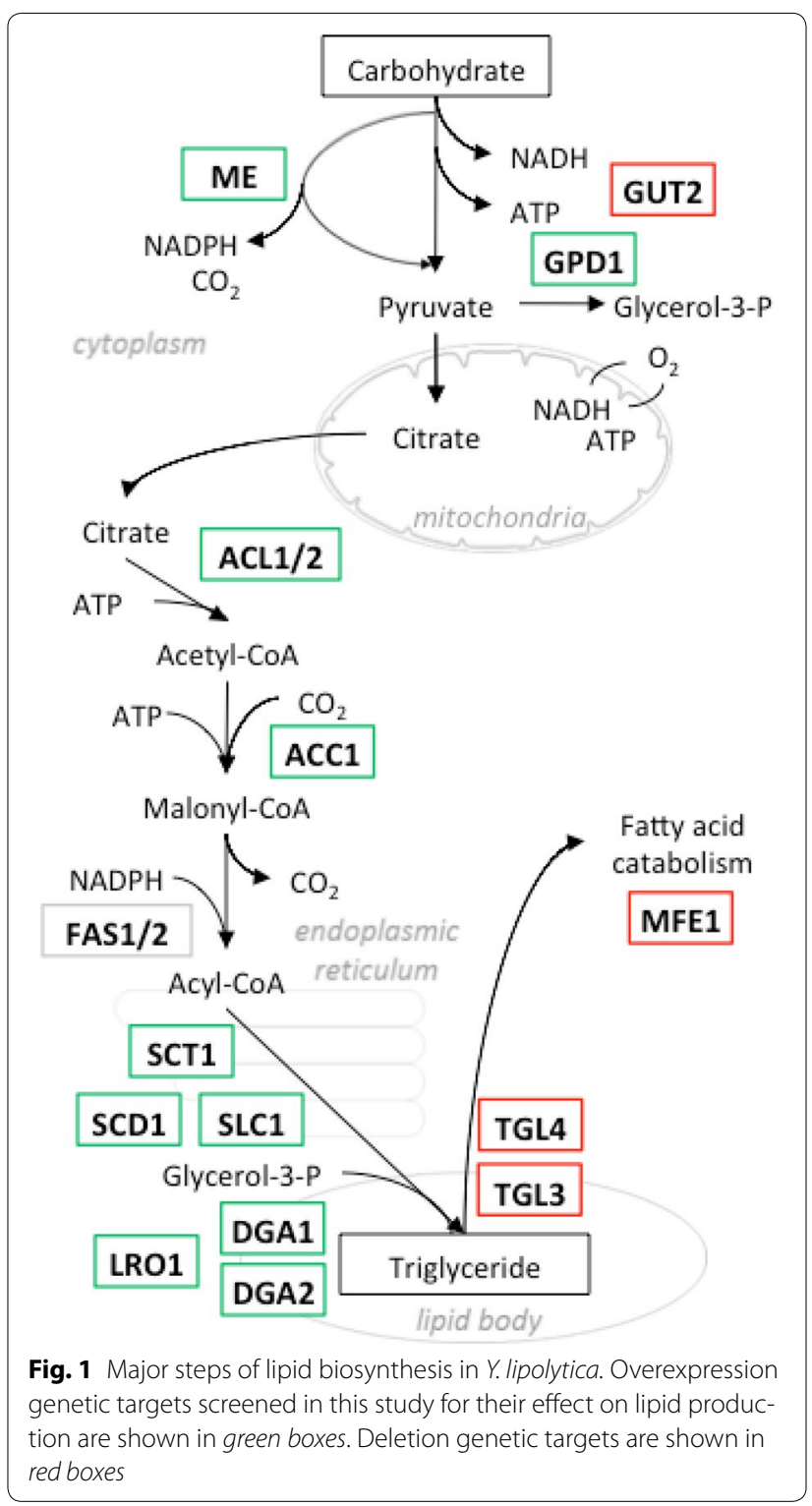

designated NS18 (obtained from NRRL \# YB-392), for future strain engineering. Previous studies have identified several endogenous genes which improve lipid production when overexpressed or deleted in Y. lipolytica $[19,21,25,31]$. One of these genes, DGA1, encoding for diacylglycerol acyltransferase type 2 , is involved in the final step of TAG synthesis [2, 19, 21, 25, 32-36] and has been a key genetic up-regulation target to increase production of TAG from glucose in independent $Y$. lipolytica studies $[19,21]$.

In order to evaluate the effect of DGA1 overexpression in NS18, the Y. lipolytica DGA1 gene (NG15) was introduced into the NS18 genome under the control of the strong constitutive GPD1 promoter to produce strain 
NS297. Although use of promoters with varied expression levels may allow for a higher degree of metabolic balancing and control, we felt strongly constitutive promoters were suitable for identifying targets for lipid biosynthesis overexpression. To produce engineered strains, 50-200 transformants were screened in 96- or 48-well plates and evaluated by fluorescence-based assay for lipid content. The top isolates were then tested in 50-mL shake flasks and the highest performing strains were grown in $1 \mathrm{~L}$ bioreactors using a high cell density fed-batch glucose fermentation process followed by gas chromotograph (GC) lipid content analysis. Lipid content measured by $\mathrm{GC}$ is reported as fatty acid methyl ester equivalents, as described in the methods section. NS297 transformants exhibited a twofold increase in lipid content compared to wild-type Y. lipolytica NS18 as evaluated by fluorescence assay (Figs. 2, 4a, b) and GC analysis (Fig. 4b).

\section{Screening heterologous DGA1 genes for increased lipid production}

Given the effectiveness of endogenous DGA1 overexpression in $Y$. lipolytica, we next sought to express DGA1 from oleaginous organisms that natively attain lipid at $50 \%$ or more of their dry weight and have publically accessible genome sequences [3, 37-40]. We chose $D G A 1$ genes from five such organisms: Rhodosporidium toruloides, Lipomyces starkeyi, Aurantiochytrium limacinum, Aspergillus terreus, and Claviceps purpurea. Three versions of the $R$. toruloides DGA1 gene were expressed in Y. lipolytica: NG49-the native $R$. toruloides $D G A 1$ gene amplified from $R$. toruloides genomic DNA; NG66-a synthetic gene containing $R$. toruloides DGA1 cDNA without introns; and NG67-a synthetic gene containing $R$. toruloides DGA1 cDNA without introns and codon optimized for expression in Y. lipolytica. Two versions of $L$. starkeyi DGA1 were expressed in Y. lipolytica: NG68-a synthetic gene containing $L$. starkeyi DGA1 cDNA without introns; and NG69-a synthetic gene containing $L$. starkeyi DGA1 cDNA without introns and codon optimized for expression in Y. lipolytica. A. limacinum (NG70), A. terreus (NG71), and C. purpurea (NG72) DGA1 genes were synthesized without introns and codon optimized for expression in Y. lipolytica. A total of nine different DGA1 genes were expressed in $Y$. lipolytica under the same strong Y. lipolytica GPD1 promoter (Table 2). Expression of all nine DGA1 genes had a positive effect on lipid content in Y. lipolytica (Fig. 2). Due to the random, non-targeted nature of integration, which can result in a range of DGA1 expression, the diversity we saw in transformants' lipid accumulation was not unexpected. Additionally, there is the potential for multiple DGA1 expression vector copies to simultaneously integrate during genetic transformation. To investigate the likelihood of our results being influenced by DNA copy number, we performed an experiment where two independent, non-linked selectable markers were cotransformed and the frequency of selectable marker coexpression was measured (Additional file 1: Figure S1). This test indicated that for the DNA loadings used in this study (approximately $1 \mu \mathrm{g}$ vector DNA/transformation) the frequency of two copies simultaneously integrating is $6 \%$ of total transformants.

Transformants that demonstrated the highest fluorescence output per optical density were generated by overexpression of $R$. toruloides DGA1 (NG66, NG67) and $L$. starkeyi DGA1 (NG68). These achieved lipid levels approximately three-fold higher than NS18 and were also higher than transformants overexpressing the native $Y$. lipolytica $D G A 1$ gene. The most effective $D G A 1$ genes came from donors that were repeatedly reported to attain

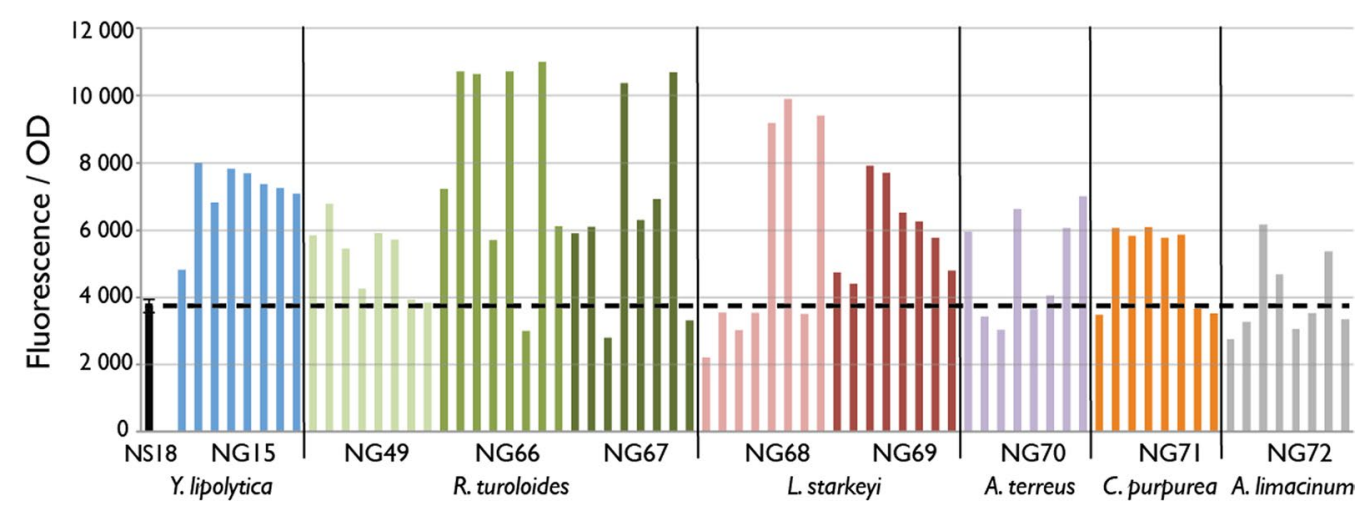

Fig. 2 Overexpression of DGA1 genes in Y. lipolytica strain NS18. Nine DGA1 genes (Table 2) under the control of the Y. lipolytica GPD1 promoter were randomly integrated into the NS18 genome and 8 transformants for each gene were analyzed by fluorescence-based lipid assay after 72 h of growth in nitrogen-limited media. The average with standard deviation from triplicate experiments is shown for the parent strain. Fluorescence was measured at excitation $486 \mathrm{~nm}$ and emission $510 \mathrm{~nm}$ and normalized by cell optical density (OD) at $600 \mathrm{~nm}$ 
Table 1 Relative lipid contents of strains with overexpressed or deleted genetic targets in addition to DGA1 overexpression

\begin{tabular}{|c|c|c|}
\hline $\begin{array}{l}\text { Genetic back- } \\
\text { ground }\end{array}$ & Function & $(\mathrm{Fl} / \mathrm{OD})_{\text {mutant }} /(\mathrm{Fl} / \mathrm{OD})_{\mathrm{NS} 125}$ \\
\hline WT & Wild-type Yarrowia lipolytica strain & $0.55 \pm 0.02$ \\
\hline DGA1 (NS125) & $\begin{array}{l}\text { Diacylglycerol acyltransferase; catalyzes the terminal step of triacylglycerol (TAG) formation, acylates } \\
\text { diacylglycerol using acyl-CoA as an acyl donor }\end{array}$ & $1.00 \pm 0.09$ \\
\hline DGA1 $\triangle$ gut2 & Mitochondrial glycerol-3-phosphate dehydrogenase & $0.95 \pm 0.12$ \\
\hline DGA1 GPD1 & NAD-dependent glycerol-3-phosphate dehydrogenase & $1.12 \pm 0.03$ \\
\hline DGA1 ME & Mitochondrial malic enzyme; catalyzes the oxidative decarboxylation of malate to pyruvate & $0.92 \pm 0.15$ \\
\hline DGA1 ACL1/2 & ATP citrate lyase $1 \& 2$ & $0.99 \pm 0.09$ \\
\hline DGA1 ACC1 & Acetyl-CoA carboxylase subunit 1 & $1.05 \pm 0.19$ \\
\hline DGA1 SCT1 & Bifunctional glycerol-3-phosphate/glycerone-phosphate O-acyltransferase & $1.03 \pm 0.01$ \\
\hline DGA1 SLC1 & 1-acylglycerol-3-phosphate O-acyltransferase & $1.25 \pm 0.07$ \\
\hline DGA1 SCD1 & $\begin{array}{l}\text { Stearoyl-CoA desaturase. Endoplasmic reticulum (ER) protein that catalyzes the } \Delta 9 \text {-cis desaturation of } \\
\text { saturated fatty acids }\end{array}$ & $0.85 \pm 0.18$ \\
\hline DGA1 DGA2 & DGAT1 acyl-CoA:diacylglycerol acyltransferase family & $1.62 \pm 0.03$ \\
\hline DGA1 LRO1 & $\begin{array}{l}\text { Acyltransferase that catalyzes diacylglycerol esterification; one of several acyltransferases that contribute } \\
\text { to triglyceride synthesis }\end{array}$ & $1.33 \pm 0.07$ \\
\hline DGA1 $\triangle \operatorname{tgl} 3$ & Bifunctional triacylglycerol lipase. Major lipid particle-localized triacylglycerol (TAG) lipase & $0.79 \pm 0.24$ \\
\hline DGA1 $\Delta \operatorname{tg} \mid 4$ & $\begin{array}{l}\text { Multifunctional lipase/hydrolase/phospholipase; triacylglycerol lipase, steryl ester hydrolase, and } \\
\text { Ca2 + -independent phospholipase A2 }\end{array}$ & $1.03 \pm 0.08$ \\
\hline DGA1 $\triangle m f e 1$ & Multifunctional enzyme, member of the peroxisomal hydroxyacyl coenzyme A dehydrogenase family & $0.89 \pm 0.03$ \\
\hline
\end{tabular}

Lipid content was measured by fluorescence-based lipid assay after $96 \mathrm{~h}$ of fermentation in 48-well plates and normalized by the value corresponding to the parental strain NS125 overexpressing DGA1 alone. All genes described here were amplified from Y. lipolytica genomic DNA and sequences are given in Additional file 1

the highest lipid contents among other oleaginous yeast strains [3, 41]. These results suggest that DGA1-specific activity and/or expression level could be a major factor driving lipid production levels in oleaginous yeasts. The effect of native $R$. toruloides DGA1 (NG49) overexpression on lipid production in $Y$. lipolytica was not as high as the effect of the synthetic versions of $R$. toruloides DGA1 genes that did not contain introns. This result may indicate that the heterologous $R$. toruloides DGA1 gene was not spliced efficiently in $Y$. lipolytica. Codon optimization of $R$. toruloides and L. starkeyi DGA1 genes did not have a positive effect on lipid production over the native cDNA sequences.

The top lipid-producing isolate expressing the $R$. toruloides DGA1 gene was designated NS281. Strains expressing DGA1 from A. limacinum, A. terreus, and $C$. purpurea did not show substantial improvements in lipid content compared to strains overexpressing the native $Y$. lipolytica DGA1 gene (Fig. 2).

\section{Screening additional genetic targets for increased lipid production in a DGA1 overexpression background}

A secondary screen was designed to test the combination of DGA1 overexpression with other targets in the lipid accumulation pathway (Fig. 1). Secondary deletion or overexpression targets, under the control of the Y. lipolytica EXP1 promoter, were integrated into strain
NS125, which overexpresses the Y. lipolytica DGA1 gene under the control of the Y. lipolytica TEF1 promoter. Targeted gene deletions were enabled by treatment of cells with hydroxyurea to arrest cell cycle division in the $\mathrm{S}$ phase during preparation of competent cells [42]. Table 1 summarizes the relative effect of secondary deletion and overexpression targets on lipid content compared to the parental strain NS125. Four overexpression targets, GPD1, SLC1, DGA2, and LRO1, had a positive effect on lipid content when combined with DGA1. Interestingly, all four of these enzymes are involved in the last steps glycerol backbone synthesis and fatty acid attachment for triacylglycerol synthesis. Overexpression of the $Y$. lipolytica DGA2 gene increased lipid content by nearly $65 \%$ compared to the parental strain NS125, which was the highest increase among the targets tested. Due to a limited number of dominant genetic markers, DGA2 alone was selected for further investigation. DGA2 is located in the endoplasmic reticulum and is hypothesized to be responsible for TAG formation in newly formed lipid bodies, while DGA1 is located on the lipid body membrane and its hypothesized function is to accumulate TAG within the same lipid body and increase its volume [43]. Considering that overexpression of homologous DGA2 alone in $Y$. lipolytica did not have as pronounced of an effect on lipid content (data not shown), the above data suggest that native DGA2 function is not limiting for 
Table 2 Description of DGA1 and DGA2 genes overexpressed in Yarrowia lipolytica

\begin{tabular}{|c|c|c|}
\hline Gene & Source & Description \\
\hline NG15 & Yarrowia lipolytica & native Y. lipolytica DGA1 gene amplified form Y. lipolytica genomic DNA \\
\hline NG49 & Rhodosporidium toruloides & native $R$. toruloides DGA1 gene amplified form $R$. toruloides genomic DNA \\
\hline NG66 & Rhodosporidium toruloides & synthetic gene containing $R$. toruloides DGA1 cDNA without introns \\
\hline NG67 & Rhodosporidium toruloides & $\begin{array}{l}\text { synthetic gene containing } R \text {. toruloides DGA1 cDNA without introns and codon optimized } \\
\text { for expression in Y. lipolytica }\end{array}$ \\
\hline NG68 & Lipomyces starkeyi & synthetic gene containing L. starkeyi DGA1 cDNA without introns \\
\hline NG69 & Lipomyces starkeyi & $\begin{array}{l}\text { synthetic gene containing L. starkeyi DGA1 cDNA without introns and codon optimized } \\
\text { for expression in Y. lipolytica }\end{array}$ \\
\hline NG70 & Aurantiochytrium limacinum & $\begin{array}{l}\text { synthetic gene containing A. limacinum DGA1 cDNA without introns and codon optimized } \\
\text { for expression in Y. lipolytica }\end{array}$ \\
\hline NG71 & Aspergillus terreus & $\begin{array}{l}\text { synthetic gene containing A. terreus DGA1 CDNA without introns and codon optimized } \\
\text { for expression in Y. lipolytica }\end{array}$ \\
\hline NG72 & Claviceps purpurea & $\begin{array}{l}\text { synthetic gene containing C. purpurea DGA1 cDNA without introns and codon optimized } \\
\text { for expression in Y. lipolytica }\end{array}$ \\
\hline NG16 & Yarrowia lipolytica & native Y. lipolytica DGA2 gene amplified form Y. lipolytica genomic DNA \\
\hline NG109 & Rhodosporidium toruloides & synthetic gene containing R. toruloides DGA2 \\
\hline NG110 & Lipomyces starkeyi & synthetic gene containing L. starkeyi DGA2 \\
\hline NG111 & Aspergillus terreus & synthetic gene containing A. terreus DGA2 \\
\hline NG112 & Claviceps purpurea & synthetic gene containing C. purpurea DGA2 \\
\hline NG113 & Chaetomium globosum & synthetic gene containing C. globosum DGA2 \\
\hline
\end{tabular}

Gene sequences are given in Additional file 1

TAG formation in NS18 wild-type $Y$. lipolytica but may become a limiting factor once DGA1 activity is abundant.

\section{Screening heterologous DGA2s for increased lipid production in a DGA1 overexpression background}

In order to identify a DGA2 with higher activity and/ or expression than that of $Y$. lipolytica, DGA2 genes (Table 2) from six donors (Y. lipolytica, $R$. toruloides, $L$. starkeyi, A. terreus, C. purpurea, Chaetomium globosum) were expressed in Y. lipolytica strains NS125 and NS281 (overexpressing $Y$. lipolytica and $R$. toruloides DGA1 genes, respectively).

The effect of different DGA2 genes on lipid content measured by fluorescence-based lipid assay is shown in Fig. 3. The effect of DGA2 overexpression was more noticeable in the NS125 strain background (Fig. 3a), possibly due to lower baseline lipid content in this strain than in NS281 (Fig. 3b). In both NS125 and NS281 strains, $C$. purpurea DGA2 (NG112) overexpression yielded the highest increase in lipid content.

\section{Deletion of TGL3 increased lipid accumulation at the end of fermentation}

TGL3 is one of two intracellular lipases responsible for the first step of lipid body localized TAG degradation in Y. lipolytica $[16,31]$. It has been suggested that TGL3 positively regulates TGL4, the primary lipase, but may not have lipase activity on its own, as it lacks a key amino acid motif that is specific for lipase activity [31]. TGL3 or TGL4 deletions in the NS125 background did not increase lipid content after $96 \mathrm{~h}$ of fermentation in smaller scale experiments (Table 1). However, as these genes are directly or indirectly involved in the breakdown of TAG, we hypothesized that their activity would be critical at the end of the bioprocess, when carbon is exhausted and cells attempt to recover stored carbon from lipids. We compared lipid levels at late time-points in the strain overexpressing $R$. toruloides NG66 DGA1 alone (NS281) and the strain combining NG66 overexpression and TGL3 deletion (NS377). Strain NS377 accumulated higher lipid content than NS281 after $140 \mathrm{~h}$ of fermentation both in $50-\mathrm{mL}$ shake flasks (data not shown) and in $1 \mathrm{~L}$ bioreactors (Fig. 4c). These results indicate that down-regulation of the TAG degradation pathway is beneficial for lipid content late in the bioprocess. Strains with a TGL4 deletion also had a positive effect on lipid content late in the fermentation but reduced overall lipid titer due to a negative effect on overall cell growth (data not shown).

\section{Combination of the best lipid accumulation genetic modifications}

In order to combine a TGL3 deletion with the R. toruloides DGA1 and C. purpurea DGA2 gene overexpressions, C. purpurea DGA2 was overexpressed in strain NS377 resulting in strain NS432 (genotype: $R t$ DGA1 nat 

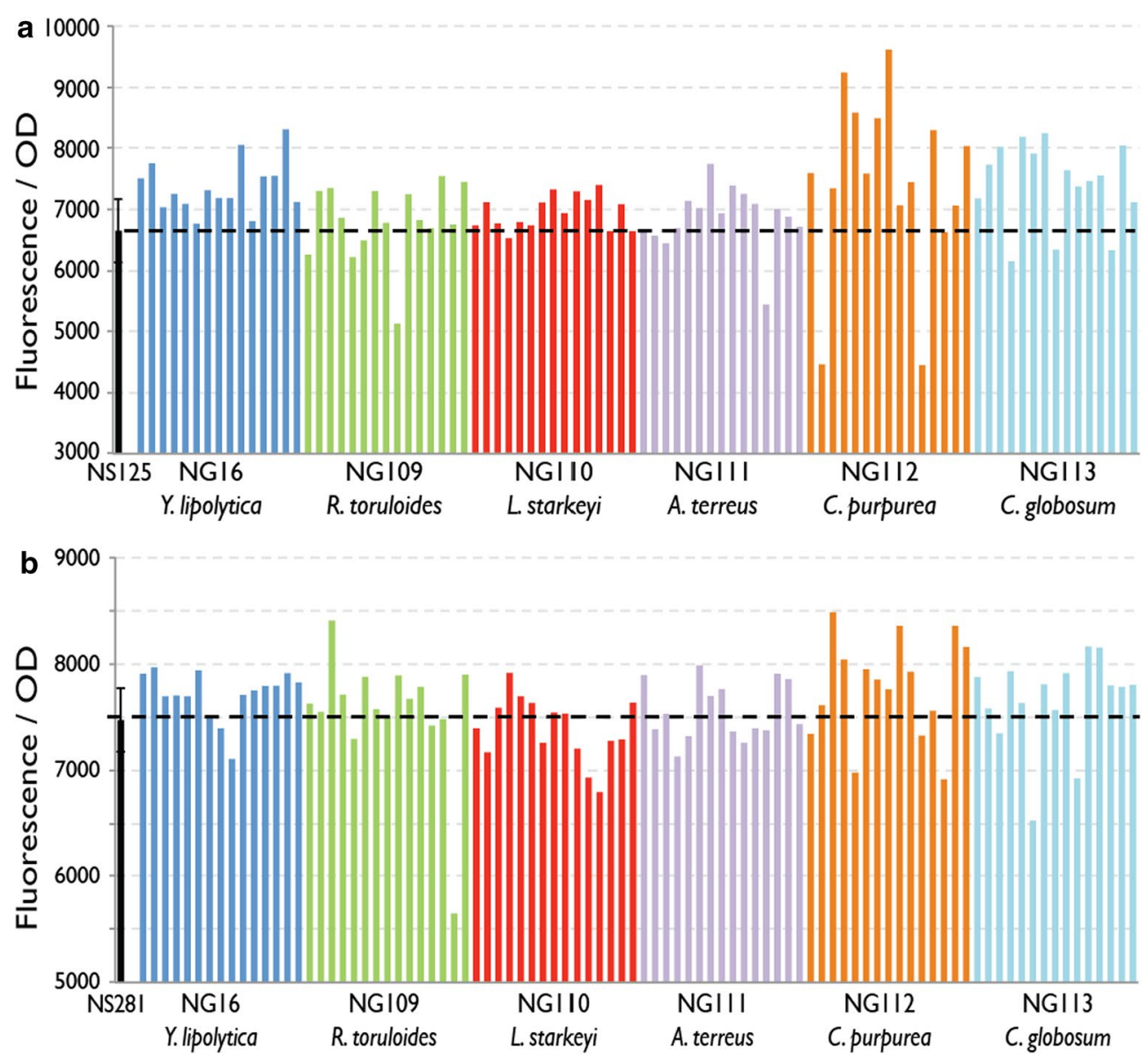

Fig. 3 Overexpression of DGA2 genes in Y. lipolytica. Six DGA2 genes (Table 2) under the control of the Y. lipolytica TEF1 promoter were overexpressed in NS125 (a) and NS281 (b) strains that overexpress DGA1 from Y. lipolytica and R. toruloides, respectively. Fifteen transformants for each gene were analyzed by fluorescence-based lipid assay after $72 \mathrm{~h}$ of growth in nitrogen-limited media. The average with standard deviation from triplicate experiments is shown for the parent strain. Fluorescence was measured at excitation $486 \mathrm{~nm}$ and emission $510 \mathrm{~nm}$ and normalized by cell optical density (OD) at $600 \mathrm{~nm}$

CpDGA2 zeo tgl3 $\Delta:: h y g$ ). NS432 reached higher lipid contents than any of the previously generated strains (Fig. 4). As expected from our results with NS377, when grown in 48-well plates or 50-mL flasks for 96 h, NS432 did not demonstrate lipid-content increase over NS450, a strain carrying only the overexpression targets $R$. toruloides DGA1 and C. purpurea DGA2 (Fig. 4a, b). Consistent with a late fermentation role for TGL3 in TAG degradation, NS432 achieved a significantly higher lipid content compared to NS450 when grown for $140 \mathrm{~h}$ in 50-mL shake flasks (data not shown) or 1-L bioreactors (Fig. 4c).

To study in depth the productivity and the yield that could be reached with NS432, two sets of conditions were explored in 1-L bioreactors. Figure 5 shows batch (a) and fed-batch (b) glucose fermentations of NS432 and wild-type NS18. The calculated lipid production parameters are shown in Table 3. Data in Fig. 5 and
Table 3 demonstrate that there is a trade-off between biomass and lipid production for the two different processes. In the batch bioprocess (carbon to nitrogen ratio of approximately 180), NS432 reached a lipid content of $77 \%$ and a yield $0.21 \mathrm{~g}$ lipid per g glucose. In the fed-batch fermentation with a carbon to nitrogen ratio of approximately 110, NS432 produced a higher lipid free cell biomass resulting in an $85 \mathrm{~g} / \mathrm{L}$ lipid titer and $0.73 \mathrm{~g} / \mathrm{L} / \mathrm{h}$ productivity, although at a slightly lower lipid content $(73 \%)$ and yield $(0.20 \mathrm{~g} / \mathrm{g})$ than in the batch process.

The stoichiometric pathway yield for TAG lipid production in Y. lipolytica based on known biochemistry for this organism has been calculated at $0.276 \mathrm{~g}$ per gram glucose [44]. However, this value does not include the expenditure of glucose to produce and maintain nonstorage lipid yeast biomass, an important consideration for applied microbial lipid production since the amount 

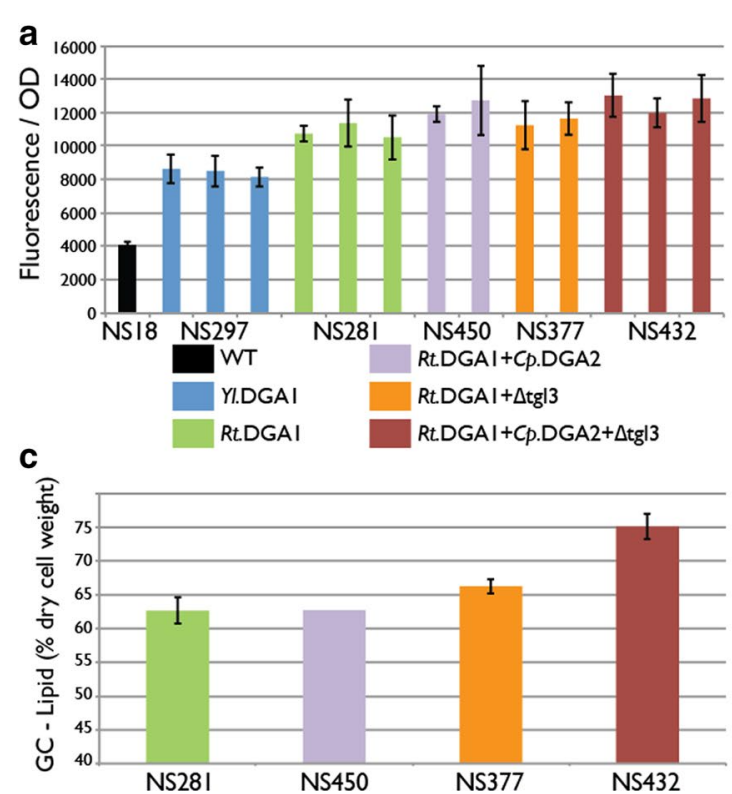

b
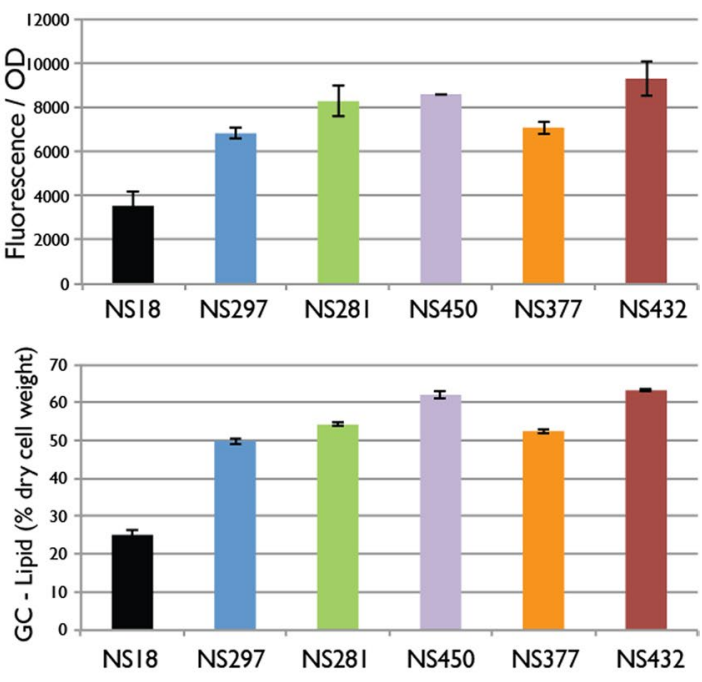

Fig. 4 Comparison of lipid accumulation in Y. lipolytica strains with different target combinations by different methods. a Strains analyzed by fluorescence assay after $96 \mathrm{~h}$ of fermentation in a 48-well plate. Two or three transformants were analyzed for each construct and average with standard deviation is shown. b Strains analyzed by fluorescence assay and GC after 96 h of fermentation in 50-mL flasks. The measurement was done in triplicates and average with standard deviation is shown. c Strains analyzed by GC after 140 h of fermentation in $1 \mathrm{~L}$ bioreactors. With exception for NS450 the measurement was done in duplicates and average with standard deviation is shown

of non-lipid biomass (i.e., catalyst) and its cell specific lipid productivity determines the rate of lipid production. As shown in Table 4, this study adds to recent literature indicating that $Y$. lipolytica can be engineered for highly effective lipid production. The batch lipid yield, fed-batch titer, and productivity reported here are among the highest reported $[22,23,44]$ and approaches the maximal values predicted by $Y$. lipolytica lipid biochemistry and co-production of non-storage lipid biomass.

\section{Conclusions}

In this study, we describe a strain engineering strategy that applied screening of endogenous and heterologous targets and target combinations for the construction of a high lipid-producing yeast biocatalyst. First, we confirmed that the overexpression of DGA1 increased lipid content in $Y$. lipolytica. A secondary screen identified genes that boosted lipid accumulation when overexpressed or deleted in combination with DGA1 overexpression. We then searched for heterologous $D G A 1$ and $D G A 2$ genes that would outperform the native enzymes in lipid accumulation and identified $R$. toruloides DGA1 and $C$. purpurea DGA2. Finally, we found that deletion of TGL3 reduces TAG degradation during the late phase of the bioprocess when nutrients are limited and lipase-mediated TAG mobilization is triggered. The yields, productivities, and titers reported in this study may further support the applied goal of developing $Y$. lipolytica for cost effective microbial lipid production. Additionally, several studies have demonstrated the ability to expand $Y$. lipolytica's substrate range to lowcost feedstocks such as sucrose [45], xylose [46], cellobiose and lignocellulosic biomass [47], and starch [48]. Researchers have also investigated continuous culture $[49,50]$ as a lower cost processing method than batch or fed-batch fermentation. The combined actions of attaining high lipid titer with low-cost feedstock utilization and advanced processing strategies should help enable use of this yeast for production of biofuels and biochemicals.

\section{Methods}

\section{Strains, media, and cultivation methods}

Wild-type Y. lipolytica strain YB-392 was obtained from the ARS (NRRL) culture collection. For routine maintenance and genetic transformation, strains were cultured in YPD (10 g/L yeast extract, $20 \mathrm{~g} / \mathrm{L}$ bacto peptone, $20 \mathrm{~g} / \mathrm{L}$ glucose) with the addition of $20 \mathrm{~g} / \mathrm{L}$ agar for solid media and $300 \mu \mathrm{g} / \mathrm{mL}$ hygromycin B (Corning), $500 \mu \mathrm{g} /$ $\mathrm{mL}$ nourseothricin (Werner Bioreagents) or $1 \mathrm{mg} / \mathrm{mL}$ zeocin (Invitrogen) for antibiotic selection. All Yarrowia strains were cultured at $30^{\circ} \mathrm{C}$.

Media and growth conditions used in this study for Escherichia coli were previously described by Sambrook 


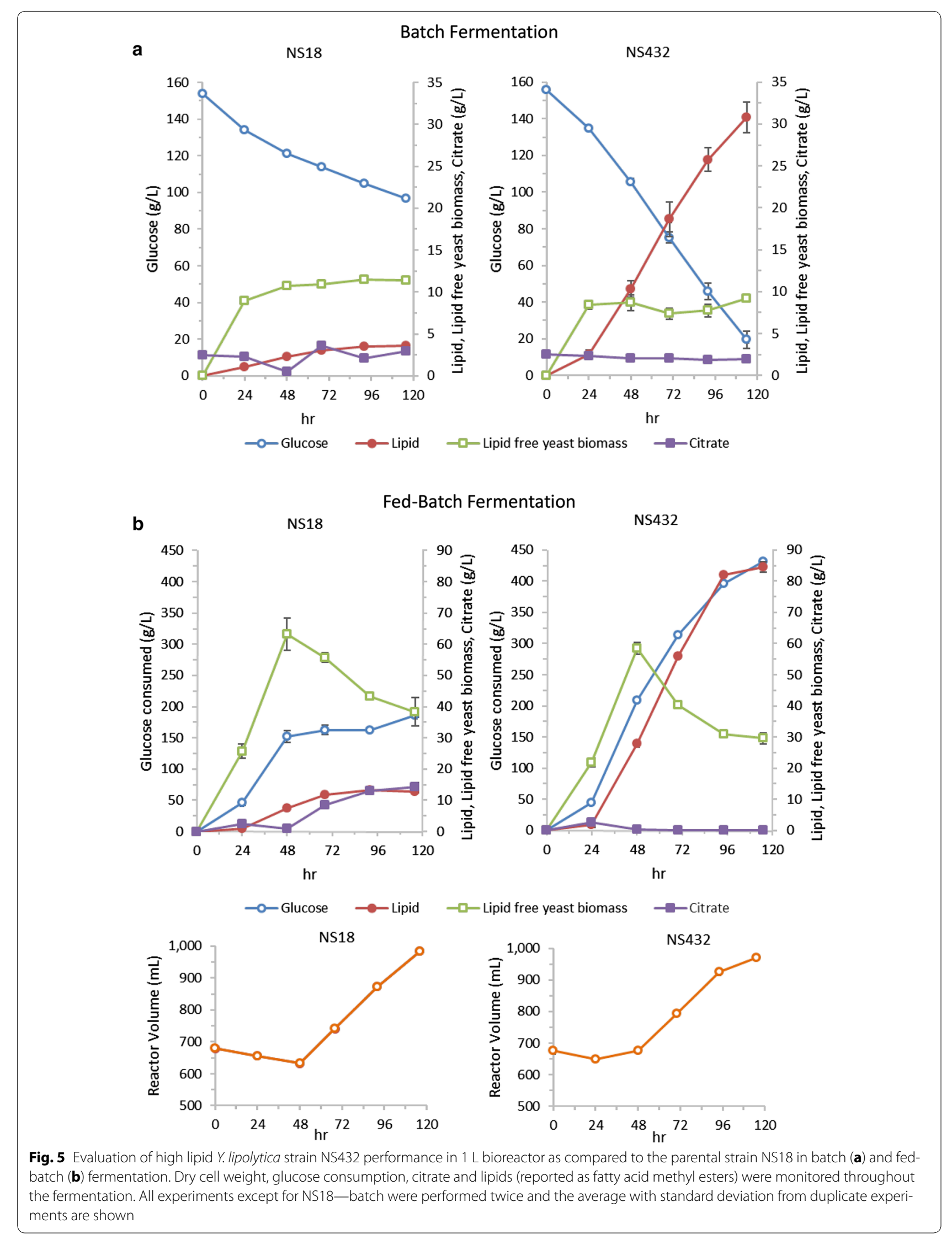


Table 3 Lipid production parameters calculated for the final time point $(120 \mathrm{~h})$ of the batch and fed-batch fermentation experiments with strains NS18 and NS432

\begin{tabular}{|c|c|c|c|c|}
\hline & \multicolumn{2}{|l|}{ NS18 } & \multicolumn{2}{|l|}{ NS432 } \\
\hline & Batch & Fed-batch & Batch & Fed-batch \\
\hline Hours post-inoculation & 116 & 116 & 114 & 115 \\
\hline Lipid content (\% w lipid/w DCW) & $24 \%$ & $25 \% \pm 4 \%$ & $77 \% \pm 2 \%$ & $73 \% \pm 2 \%$ \\
\hline Titer (g lipid/L) & 3.6 & $12.8 \pm 1.0$ & $30.8 \pm 1.8$ & $84.5 \pm 1.7$ \\
\hline Productivity (g lipid $\mathrm{L}^{-1} \mathrm{~h}^{-1}$ ) & 0.03 & $0.11 \pm 0.01$ & $0.27 \pm 0.02$ & $0.73 \pm 0.01$ \\
\hline Cell specific productivity ${ }^{a}$ (g lipid g lipid free DCW ${ }^{-1} h^{-1}$ ) & 0.002 & $0.003 \pm 0.001$ & $0.048 \pm 0.006$ & $0.044 \pm 0.001$ \\
\hline Yield (g lipid/g glucose consumed) ${ }^{b}$ & 0.06 & $0.07 \pm 0.01$ & $0.21 \pm 0.004$ & $0.20 \pm 0.004$ \\
\hline
\end{tabular}

All experiments except for NS18 - batch were performed twice and the average with standard deviation from duplicate experiments is shown

a Cell specific productivity calculated over 20-70-h post-inoculation

b Yields calculated for batch cultivation account for a measured $10 \%$ volume loss due to sampling and aeration over the course of fermentation

Table 4 Recently reported literature values for lipid titer, yield, and productivity with engineered Yarrowia lipolytica strains

\begin{tabular}{|c|c|c|c|c|c|c|c|c|c|}
\hline $\begin{array}{l}\text { Parental } \\
\text { strain }\end{array}$ & Strain & $\begin{array}{l}\text { Lipid path- } \\
\text { way genetic } \\
\text { engineering }\end{array}$ & Process & $\begin{array}{l}\text { Sugar } \\
\text { consumed } \\
(g / L)\end{array}$ & $\begin{array}{l}\text { Lipid titer } \\
\text { (g/L) }\end{array}$ & $\begin{array}{l}\text { Overall } \\
\text { yield }(g / g)\end{array}$ & $\begin{array}{l}\text { Overall } \\
\text { volumetric } \\
\text { productiv- } \\
\text { ity }(\mathrm{g} / \mathrm{L} / \mathrm{h})\end{array}$ & $\begin{array}{l}\text { Cell specific } \\
\text { productiv- } \\
\text { ity }(g / g / h)\end{array}$ & Reference \\
\hline po1g & MTYL037 & $\begin{array}{l}\text { control strain } \\
\quad(\text { ura }+ \text { lacz) }\end{array}$ & Batch & 80 & 2.5 & 0.03 & 0.02 & 0.002 & [19] \\
\hline polg & MTYL065 & DGA1 ACC1 & Batch & 80 & 17.6 & 0.20 & 0.14 & 0.017 & [19] \\
\hline po1g & YL-ad9 & $\begin{array}{l}\text { DGA1 ACC1 } \\
\text { SGD1 }\end{array}$ & $\begin{array}{l}\text { Fed- } \\
\text { batch }\end{array}$ & 235 & 55 & 0.23 & 0.71 & 0.038 & [22] \\
\hline polf & polfleu + ura + & control strain & Batch & 80 & 3 & 0.04 & 0.02 & 0.001 & [21] \\
\hline polf & $\begin{array}{l}\text { pex10 mfe1 } \\
\text { leu + ura + DGA1 }\end{array}$ & $\begin{array}{l}\text { DGA1 } \\
\Delta \text { pex10 } \\
\Delta \text { mfe1 }\end{array}$ & Batch & 80 & 16.1 & 0.20 & 0.11 & 0.017 & [21] \\
\hline polf & $\begin{array}{l}\text { pex10 mfe1 } \\
\text { leu + ura + DGA1 }\end{array}$ & $\begin{array}{l}\text { DGA1 } \\
\triangle \text { pex10 } \\
\Delta \mathrm{mfe} 1\end{array}$ & Batch & 160 & 25.3 & 0.16 & 0.21 & - & [21] \\
\hline polf & $\begin{array}{l}\text { L36 DGA1 } \\
\quad \text { leu + ura + }\end{array}$ & $\begin{array}{l}\text { DGA1 mga2- } \\
\text { G643R }\end{array}$ & $\begin{array}{l}\text { Fed- } \\
\text { batch }\end{array}$ & 160 & 25 & 0.21 & 0.13 & 0.018 & [24] \\
\hline polf & E26E1 & $\begin{array}{l}\text { DGA1 } \\
\qquad \text { pex10 } \\
\text { Amfe1 uga- } \\
\text { P209S }\end{array}$ & Batch & 160 & 39.1 & 0.24 & 0.56 & 0.035 & [23] \\
\hline pold & JMY2593 & $\begin{array}{l}\text { control strain } \\
\text { (SUC2) }\end{array}$ & Batch & 60 & 2.6 & 0.04 & 0.04 & 0.004 & [26] \\
\hline pold & JMY3582 & $\begin{array}{l}\text { DGA2(x3) } \\
\triangle \text { dga1 } \\
\Delta \text { dga2 } \\
\Delta \text { lro1 } \triangle \text { are } 1\end{array}$ & Batch & 60 & 6.5 & 0.11 & 0.09 & 0.010 & [26] \\
\hline NS18 & NS18 & wild-type & Batch & 60 & 3.6 & 0.06 & 0.04 & 0.002 & this study \\
\hline NS18 & NS432 & $\begin{array}{l}\text { DGA1 DGA2 } \\
\Delta \operatorname{tgl} 3\end{array}$ & Batch & 140 & 30.8 & 0.21 & 0.27 & 0.048 & this study \\
\hline NS18 & NS432 & $\begin{array}{l}\text { DGA1 DGA2 } \\
\Delta \operatorname{tgl} 3\end{array}$ & $\begin{array}{l}\text { Fed- } \\
\text { batch }\end{array}$ & 430 & 84.5 & 0.20 & 0.73 & 0.044 & this study \\
\hline
\end{tabular}

Where necessary, values for overall and cell specific productivities were estimated from figures of cited references $[24,26]$

and Russell [51], those for Saccharomyces cerevisiae by Shanks et al. [52], and those for Y. lipolytica by Barth and Gaillardin [9].
Medium used for fluorescence assay in 96-well or 48-well plates, and shake flasks was: urea $(0.5 \mathrm{~g} / \mathrm{L})$, yeast extract $(1.5 \mathrm{~g} / \mathrm{L})$, casamino acids $(0.85 \mathrm{~g} / \mathrm{L})$, YNB without 
amino acids and ammonium sulfate $(1.7 \mathrm{~g} / \mathrm{L})$, glucose $(100 \mathrm{~g} / \mathrm{L})$, potassium hydrogen phthalate buffer adjusted to $\mathrm{pH} 5.5(5.1 \mathrm{~g} / \mathrm{L})$.

Initial concentrations of medium for $1 \mathrm{~L}$ batch and fed-batch bioreactors was: glucose $\mathrm{T}_{0}(150 \mathrm{~g} / \mathrm{L})$, sensient amberex 1003 yeast extract $(3 \mathrm{~g} / \mathrm{L})$, sensient amberferm 4500 corn peptone $(0.1 \mathrm{~g} / \mathrm{L}), \mathrm{KH}_{2} \mathrm{PO}_{4}$ (4 g/L), $\mathrm{MgSO}_{4} \cdot 7 \mathrm{H}_{2} \mathrm{O}(2 \mathrm{~g} / \mathrm{L}), \mathrm{CaCl}_{2} \cdot 6 \mathrm{H}_{2} \mathrm{O}(0.8 \mathrm{~g} / \mathrm{L})$, $\mathrm{NaCl}(0.4 \mathrm{~g} / \mathrm{L})$, thiamine $(12 \mathrm{mg} / \mathrm{L})$, biotin $(1 \mathrm{mg} / \mathrm{L})$, trace elements $\left[\mathrm{Na}_{2} \mathrm{MoO}_{4} \cdot 2 \mathrm{H}_{2} \mathrm{O} \quad\left(\begin{array}{ll}160 & \mathrm{mg} / \mathrm{L}\end{array}\right)\right.$, $\mathrm{CuSO}_{4} \cdot 5 \mathrm{H}_{2} \mathrm{O} \quad(0.2 \mathrm{mg} / \mathrm{L}), \quad \mathrm{H}_{3} \mathrm{BO}_{3} \quad(40 \mathrm{mg} / \mathrm{L})$, $\mathrm{MnSO}_{4} \cdot \mathrm{H}_{2} \mathrm{O} \quad(180 \mathrm{mg} / \mathrm{L}), \quad \mathrm{FeCl}_{2} \cdot 6 \mathrm{H}_{2} \mathrm{O} \quad(75 \mathrm{mg} / \mathrm{L})$, $\mathrm{ZnSO}_{4} \cdot 7 \mathrm{H}_{2} \mathrm{O}(20 \mathrm{mg} / \mathrm{L}$ )], and Antifoam 204 (SigmaAldrich) $(1 \mathrm{~mL} / \mathrm{L})$. For the batch process, $\left(\mathrm{NH}_{4}\right)_{2} \mathrm{SO}_{4}$ was added at $0.5 \mathrm{~g} / \mathrm{L}$ and in the fed-batch process at $11 \mathrm{~g} / \mathrm{L}$ for the initial reactor volume. Process parameters included an inoculum volume of $2 \%$ from an overnight shake flask in YPD, pH control at 3.5 automatically adjusted with $10 \mathrm{~N}$ sodium hydroxide, a temperature of $30{ }^{\circ} \mathrm{C}$, aeration at $0.3 \mathrm{vvm}$ air, and agitation at $1000 \mathrm{rpm}$ for both processes. For the fed-batch process a glucose substrate feed was initiated after batch glucose consumption at a rate of $6.5 \mathrm{~mL} / \mathrm{h}$ from $420 \mathrm{~mL}$ of a $75 \% \mathrm{w} / \mathrm{v}$ concentrated glucose stock solution. The initial batch volume was $680 \mathrm{~mL}$.

\section{Genetic transformation}

$Y$. lipolytica competent cells were prepared following the protocol of Chen et al. [53]. Cells were grown overnight spread on YPD plates, and grown cells were transferred from the plate with $1 \mathrm{~mL}$ water. $50 \mu \mathrm{l}$ was aliquoted per transformation reaction, cells were centrifuged and the supernatant was discarded. $9 \mu \mathrm{l}$ of each PCR product (without purification) and $92 \mu \mathrm{l}$ of transformation mix $(80 \mu \mathrm{L} 60 \%$ polyethylene glycol 4000, $5 \mu \mathrm{l} 2 \mathrm{M}$ dithiothreitol, $5 \mu \mathrm{l} 2 \mathrm{M}$ lithium acetate $\mathrm{pH} 6,2 \mu \mathrm{l} 10 \mathrm{mg} / \mathrm{mL}$ single-stranded salmon sperm DNA) was added to the cell pellet. The transformation reaction was mixed well by vortexing and heat shocked at $39{ }^{\circ} \mathrm{C}$ for $1 \mathrm{~h}$. Cells were centrifuged, the supernatant discarded, cells were resuspended in $1 \mathrm{~mL}$ YPD, transferred to culture tubes and cultured overnight before plating on selective media (YPD containing hygromycin $\mathrm{B}$, zeocin or nourseothricin).

\section{Plasmid construction \\ Gene overexpression}

Standard molecular biology techniques were used in this study [51]. Restriction enzymes and DNA polymerase were purchased from New England Biolabs (Ipswich, MA). Descriptions of plasmids used for gene overexpressions and gene sequences are presented in Additional file 1.
For DGA1 overexpressions, the linear expression construct included an expression cassette for different $D G A 1$ genes and for the nat1 gene used as a marker for selection of random chromosomal integrants with nourseothricin. For DGA2 overexpressions, the linear expression construct included an expression cassette for DGA2 genes and for the ble gene used as a marker for selection with zeocin. For each expression construct 15 transformants were analyzed by fluorescence lipid assay.

For overexpression of secondary target genes, the linear expression construct included an expression cassette for the gene of interest and for the $h p h$ gene used as a marker for selection with hygromycin.

\section{Gene deletion in Yarrowia lipolytica}

The Y. lipolytica TGL3, GUT2, TGL4 and MFE1 genes were deleted as follows: A two-fragment deletion cassette was amplified by PCR from a plasmid containing the hygromycin resistance gene $h p h$ such that the $h p h$ gene was split into two fragments that overlapped and were flanked by $\sim 50$ bp of homology to the upstream and downstream regions of the coding sequence (Primers summarized on Additional file 1: Table S1). The resulting PCR fragments were co-transformed. Y. lipolytica grown overnight on solid YPD media was used to inoculate a $25 \mathrm{~mL}$ YPD culture at $\mathrm{OD}_{600}=0.5$. After $3 \mathrm{~h}$ of growth, $50 \mathrm{mM}$ hydroxyurea was added [42]. Cells were harvested $2 \mathrm{~h}$ post hydroxyurea addition, and the standard transformation protocol was followed with washed cell pellets. Hygromycin resistant colonies were screened by PCR to confirm the absence of the gene and the presence of a specific product.

\section{Lipid content measurement by fluorescence assay}

Strains patched on YPD agar media were inoculated into fluorescent assay media volumes of $1.5 \mathrm{~mL}$ for 24-well plates or $0.6 \mathrm{~mL}$ for 96 -well plates or $50 \mathrm{~mL}$ for shake flasks. Plates were incubated at $30{ }^{\circ} \mathrm{C}$ for $96 \mathrm{~h}$ and $900 \mathrm{rpm}$, at 70-90 \% humidity in an Infors Multitron ATR shaker. The shake flasks were incubated at $30{ }^{\circ} \mathrm{C}$ for $96 \mathrm{~h}$ and $200 \mathrm{rpm}$ in a New Brunswick Scientific shaker. To measure fluorescence, $20 \mu \mathrm{L}$ cells were mixed with $20 \mu \mathrm{L}$ of $100 \%$ ethanol in microplates and incubated at $4{ }^{\circ} \mathrm{C}$ for $30 \mathrm{~min}$. A master mix containing $1 \mathrm{M}$ potassium iodide, $1 \mathrm{mM}$ bodipy 493/503, $0.5 \mu \mathrm{L}$ dimethyl sulfoxide, $1.5 \mu \mathrm{L}$ of $60 \%$ PEG 4000 and $27 \mu \mathrm{L}$ water was then aliquoted into Costar black well/clear bottom plates $(80 \mu \mathrm{L} /$ well) and $20 \mu \mathrm{L}$ of the ethanol/cell mix was added. Fluorescence was measured with a SpectraMax M2 spectrophotometer (molecular devices) at excitation $484 \mathrm{~nm}$ and emission $510 \mathrm{~nm}$. The optical density (OD) at $600 \mathrm{~nm}$ was measured in the same plate. Fluorescence correlated with lipid content measured by GC. 


\section{Lipid extraction and GC analysis}

Dried biomass, prepared by lyophilization of $1 \mathrm{~mL}$ fermentation samples washed with an equal volume of water, was subjected to acid-catalyzed transesterification with $0.5 \mathrm{~N}$ hydrochloric acid in methanol $(20 \times 1 \mathrm{~mL}$ ampule, Sigma $)$ at $85^{\circ} \mathrm{C}$ for $90 \mathrm{~min}$. After the transesterification was completed, the lipid-soluble components of the reaction mixture were separated from the water-soluble components using a two-phase liquid extraction by adding water and isooctane and subsequently analyzed with a capillary gas chromatograph $(\mathrm{GC})$ equipped with a robotic injector, flame ionization detector (Thermo Scientific Trace GC Ultra with AS 3000 autosampler) and HP-INNOWAX capillary column $(30 \mathrm{~m} \times 0.25 \mathrm{~mm} \times 0.15$ micrometers, Agilent). Quantification of the methyl-ester products was achieved with use of both an internal standard (13:0 or 15:0 fatty acid) and various concentrations of an external standard mixture (NHI-D, Supelco Analytical, Bellefonte, PA) of fatty acid methyl esters (FAMEs). Lipids were reported as FAME equivalents of 16:0, 16:1, 18:0, 18:1, and 18:2 fatty acids, e.g., the amount of FAME resulting from lipid extraction and transesterification after accounting for transesterification efficiency via the internal standard.

\section{Additional file}

Additional file 1: Contains a description of the multi-copy integration experiment, gene overexpression vectors, lipid biosynthesis pathway gene sequences used in this study, and primers used to construct gene knockout targets.

\section{Abbreviations}

TAG: triacylglycerol; GC: gas chromatography; cDNA: complementary DNA; YPD: yeast extract, peptone, dextrose medium; YNB: yeast nitrogen base medium; FAME: fatty acid methyl ester; OD: optical density; WT: wild-type organism.

\section{Authors' contributions \\ $J F, V T, A K, R N, M H, J S$, and EB designed and performed molecular biology, metabolic engineering, and micro-scale lipid assay experiments. EG, AC, KM designed and performed bioreactor fermentation experiments. DC and JA performed analytical measurements. CS and GS conceived the study. JF, VT, JS, GS, and EB wrote and reviewed the manuscript. All authors read and approved the final manuscript.}

\begin{abstract}
Author details
${ }^{1}$ Total New Energies, 5858 Horton Street, Emeryville, CA 94610, USA. ${ }^{2}$ Novogy, Inc., 85 Bolton Street, Cambridge, MA 02140, USA. ${ }^{3}$ Department of Chemical Engineering, Massachusetts Institute of Technology, 77 Massachusetts Ave., Cambridge, MA 02139, USA. ${ }^{4}$ Present Address: Twist Bioscience, 455 Mission Bay Blvd South, San Francisco, CA 94158, USA. ${ }^{5}$ Present Address: Evelo Therapeutics, 620 Memorial Dr., Cambridge, MA 02139, USA.
\end{abstract}

\section{Acknowledgements}

We thank Drs. Cornel Verduyn and Hans van Dijken for helpful and stimulating discussions during the preparation of this manuscript. The study was supported by Novogy, Inc.

\section{Competing interests}

The authors are current employees, former employees, or otherwise affiliated with Novogy, Inc., which has a commercial interest in the strains described in this study. The authors declare no other non-financial competing interests.

Received: 23 December 2015 Accepted: 21 March 2016

Published online: 31 March 2016

\section{References}

1. Donot F, Fontana A, Baccou JC, Strub C, Schorr-Galindo S. Single cell oils (SCOs) from oleaginous yeasts and moulds: production and genetics. Biomass Bioenergy. 2014;68:135-50.

2. Beopoulos A, Cescut J, Haddouche R, Uribelarrea J-L, Molina-Jouve C, Nicaud J-M. Yarrowia lipolytica as a model for bio-oil production. Prog Lipid Res. 2009:48:375-87.

3. Ratledge C, Wynn JP. The biochemistry and molecular biology of lipid accumulation in oleaginous microorganisms. Adv Appl Microbiol. 2002;51:1-51.

4. Bati N, Hammond EG, Glatz BA. Biomodification of fats and oils: trials with Candida lipolytica. J Am Oil Chem Soc. 1984;61:1743-6.

5. Papanikolaou S, Chevalot I, Galiotou-Panayotou M, Komaitis M, Marc I, Aggelis G. Industrial derivative of tallow: a promising renewable substrate for microbial lipid, single-cell protein and lipase production by Yarrowia lipolytica. Electron J Biotechn. 2007;10:425-35.

6. Ledesma-Amaro R, Nicaud J-M. Yarrowia lipolytica as a biotechnological chassis to produce usual and unusual fatty acids. Prog Lipid Res. 2016;61:40-50.

7. Beopoulos A, Verbeke J, Bordes F, Guicherd M, Bressy M, Marty A, Nicaud J-M. Metabolic engineering for ricinoleic acid production in the oleaginous yeast Yarrowia lipolytica. Appl Microbiol Biotechnol. 2014;98:251-62.

8. Zhu Q, Jackson EN. Metabolic engineering of Yarrowia lipolytica for industrial applications. Curr Opin Biotechnol. 2015;36:65-72.

9. Barth G, Gaillardin C. Yarrowia lipolytica. Berlin: Springer; 1996:313-388.

10. Gonçalves FAG, Colen G, Takahashi JA. Yarrowia lipolytica and its multiple applications in the biotechnological industry. Scientific World J. 2014:2014:476207-14

11. Fischer CR, Klein-Marcuschamer D, Stephanopoulos G. Selection and optimization of microbial hosts for biofuels production. Metab Eng. 2008;10:295-304

12. Lee SK, Chou H, Ham TS, Lee TS, Keasling JD. Metabolic engineering of microorganisms for biofuels production: from bugs to synthetic biology to fuels. Curr Opin Biotechnol. 2008;19:556-63.

13. Papanikolaou S, Aggelis G. Part I: lipids of oleaginous yeasts. Biochemistry of single cell oil production. Eur J Lipid Sci Tech. 2011;113:1031-51.

14. Papanikolaou S, Aggelis G. Lipids of oleaginous yeasts. Part II: technology and potential applications. Eur J Lipid Sci Tech. 2011;113:1052-73.

15. Zweytick D, Athenstaedt K, Daum G. Intracellular lipid particles of eukaryotic cells. Biochim Biophys Acta. 2000;1469:101-20.

16. Koch B, Schmidt C, Daum G. Storage lipids of yeasts: a survey of nonpolar lipid metabolism in Saccharomyces cerevisiae, Pichia pastoris, and Yarrowia lipolytica. FEMS Microbiol Rev. 2014;38:892-915.

17. Grillitsch K, Connerth M, Köfeler H, Arrey TN, Rietschel B, Wagner B, Karas M, Daum G. Lipid particles/droplets of the yeast Saccharomyces cerevisiae revisited: lipidome meets proteome. Biochim Biophys Acta. 2011;1811:1165-76.

18. Fei W, Shui G, Zhang Y, Krahmer N, Ferguson C, Kapterian TS, Lin RC, Dawes IW, Brown AJ, Li P, Huang X, Parton RG, Wenk MR, Walther TC, Yang $\mathrm{H}$. A role for phosphatidic acid in the formation of "supersized" lipid droplets. PLoS Genet. 2011;7:e1002201.

19. Tai M, Stephanopoulos G. Engineering the push and pull of lipid biosynthesis in oleaginous yeast Yarrowia lipolytica for biofuel production. Metab Eng. 2013;15:1-9.

20. Beopoulos A, Mrozova Z, Thevenieau F, Le Dall M-T, Hapala I, Papanikolaou S, Chardot T, Nicaud J-M. Control of lipid accumulation in the yeast Yarrowia lipolytica. Appl Environ Microbiol. 2008;74:7779-89.

21. Blazeck J, Hill A, Liu L, Knight R, Miller J, Pan A, Otoupal P, Alper HS. Harnessing Yarrowia lipolytica lipogenesis to create a platform for lipid and biofuel production. Nat Commun. 2014;5:3131. 
22. Qiao K, Imam Abidi SH, Liu H, Zhang H, Chakraborty S, Watson N, Kumaran Ajikumar P, Stephanopoulos P. Engineering lipid overproduction in the oleaginous yeast Yarrowia lipolytica. Metab Eng. 2015;29:56-65.

23. Liu L, Pan A, Spofford C, Zhou N, Alper HS. An evolutionary metabolic engineering approach for enhancing lipogenesis in Yarrowia lipolytica. Metab Eng. 2015;29:36-45.

24. Liu L, Markham K, Blazeck J, Zhou N, Leon D, Otoupal P, Alper HS. Surveying the lipogenesis landscape in Yarrowia lipolytica through understanding the function of a Mga2p regulatory protein mutant. Metab Eng. 2015;31:102-11

25. Beopoulos A, Haddouche R, Kabran P, Dulermo T, Chardot T, Nicaud J-M. Identification and characterization of DGA2, an acyltransferase of the DGAT1 acyl-CoA:diacylglycerol acyltransferase family in the oleaginous yeast Yarrowia lipolytica. New insights into the storage lipid metabolism of oleaginous yeasts. Appl Microbiol Biotechnol. 2012;93:1523-37.

26. Gajdoš P, Nicaud J-M, Rossignol T, Čertík M. Single cell oil production on molasses by Yarrowia lipolytica strains overexpressing DGA2 in multicopy. Appl Microbiol Biotechnol. 2015:1-10.

27. Athenstaedt K, Jolivet P, Boulard C, Zivy M, Negroni L, Nicaud J-M, Chardot T. Lipid particle composition of the yeast Yarrowia lipolytica depends on the carbon source. Proteomics. 2006;6:1450-9.

28. Courchesne NMD, Parisien A, Wang B, Lan CQ. Enhancement of lipid production using biochemical, genetic and transcription factor engineering approaches. J Biotechnol. 2009;141:31-41.

29. Zhang S, Skerker JM, Rutter CD, Maurer MJ, Arkin AP, Rao CV. Engineering Rhodosporidium toruloides for increased lipid production. Biotechnol Bioeng. 2015. doi:10.1002/bit.25864

30. Meyer K, Stecca KL. Plant seeds with altered storage compound levels, related constructs and methods involving genes encoding oxidoreductase motif polypeptides. 2013. WO2011109618 A2.

31. Dulermo T, Tréton B, Beopoulos A, Kabran Gnankon AP, Haddouche R, Nicaud J-M. Characterization of the two intracellular lipases of $Y$. lipolytica encoded by TGL3 and TGL4 genes: new insights into the role of intracellular lipases and lipid body organisation. Biochim Biophys Acta. 2013;1831:1486-95.

32. Athenstaedt K. YALIOE32769 g (DGA1) and YALIOE16797 g (LRO1) encode major triacylglycerol synthases of the oleaginous yeast Yarrowia lipolytica. Biochim Biophys Acta. 2011;1811:587-96.

33. Oelkers P, Cromley D, Padamsee M, Billheimer JT, Sturley SL. The DGA1 gene determines a second triglyceride synthetic pathway in yeast. J Biol Chem. 2002;277:8877-81.

34. Valanne S, Wang J-H, Rämet M. The Drosophila Toll signaling pathway. J Immunol. 2011;186:649-56.

35. Reed DE, Huang XM, Wohlschlegel JA, Levine MS, Senger K. DEAF-1 regulates immunity gene expression in Drosophila. Proc Natl Acad Sci USA. 2008;105:8351-6.

36. Stark A, Lin MF, Kheradpour P, Pedersen JS, Parts L, Carlson JW, Crosby MA, Rasmussen MD, Roy S, Deoras AN, Ruby JG, Brennecke J, Curators HF, Project BDG, Hodges E, Hinrichs AS, Caspi A, Paten B, Park S-W, Han MV, Maeder ML, Polansky BJ, Robson BE, Aerts S, van Helden J, Hassan B, Gilbert DG, Eastman DA, Rice M, Weir M, et al. Discovery of functional elements in 12 Drosophila genomes using evolutionary signatures. Nature. 2007:450:219-32.
37. Sitepu IR, Sestric R, Ignatia L, Levin D, German JB, Gillies LA, Almada LAG, Boundy-Mills KL. Manipulation of culture conditions alters lipid content and fatty acid profiles of a wide variety of known and new oleaginous yeast species. Bioresour Technol. 2013;144:360-9.

38. Liang $\mathrm{M}-\mathrm{H}$, Jiang J-G. Advancing oleaginous microorganisms to produce lipid via metabolic engineering technology. Prog Lipid Res. 2013;52:395-408

39. Ageitos JM, Vallejo JA, Veiga-Crespo P, Villa TG. Oily yeasts as oleaginous cell factories. Appl Microbiol Biotechnol. 2011;90:1219-27.

40. Kaneko H, Hosohara M, Tanaka M, Itoh T. Lipid composition of 30 species of yeast. Lipids. 1976;11:837-44.

41. Zhu Z, Zhang S, Liu H, Shen H, Lin X, Yang F, Zhou YJ, Jin G, Ye M, Zou H, Zou H, Zhao ZK. A multi-omic map of the lipid-producing yeast Rhodosporidium toruloides. Nat Commun. 2012;3:1112.

42. Tsakraklides V, Brevnova E, Stephanopoulos G, Shaw AJ. Improved gene targeting through cell cycle synchronization. PLoS One. 2015. doi:10.1371/journal.pone.01334.

43. Wilfling F, Wang H, Haas JT, Krahmer N, Gould TJ, Uchida A, Cheng J-X, Graham M, Christiano R, Fröhlich F, Liu X, Buhman KK, Coleman RA, Bewersdorf J, Farese RV, Walther TC. Triacylglycerol synthesis enzymes mediate lipid droplet growth by relocalizing from the ER to lipid droplets. Dev Cell. 2013;24:384-99.

44. Ratledge C. The role of malic enzyme as the provider of NADPH in oleaginous microorganisms: a reappraisal and unsolved problems. Biotechnol Lett. 2014;36:1557-68.

45. Lazar Z, Rossignol T, Verbeke J, Crutz-Le Coq A-M, Nicaud J-M, Robak M. Optimized invertase expression and secretion cassette for improving Yarrowia lipolytica growth on sucrose for industrial applications. J Ind Microbiol Biotechnol. 2013:40:1273-83.

46. Stephanopoulos G, Tai M. Engineered microbes and methods for microbial oil overproduction from cellulosic materials. US Patent 20130344548 A1 2013.

47. Wei H, Wang W, Alahuhta M, Vander Wall T, Baker JO, Taylor LE, Decker SR, Himmel ME, Zhang M. Engineering towards a complete heterologous cellulase secretome in Yarrowia lipolytica reveals its potential for consolidated bioprocessing. Biotechnol Biofuels. 2014;7:148.

48. Ledesma-Amaro R, Dulermo T, Nicaud JM. Engineering Yarrowia lipolytica to produce biodiesel from raw starch. Biotechnol Biofuels. 2015;8:148.

49. Papanikolaou S, Aggelis G. Lipid production by Yarrowia lipolytica growing on industrial glycerol in a single-stage continuous culture. Bioresour Technol. 2002;82:43-9.

50. Rakicka M, Lazar Z, Dulermo T, Fickers P, Nicaud JM. Lipid production by the oleaginous yeast Yarrowia lipolytica using industrial by-products under different culture conditions. Biotechnol Biofuels. 2015;8:104.

51. Sambrook J, Russell DW. Molecular Cloning: A Laboratory Manual. Cold Spring Harbor: Cold Spring Harbor Lab Press; 2001.

52. Shanks RMQ, Caiazza NC, Hinsa SM, Toutain CM, O'Toole GA. Saccharomyces cerevisiae-based molecular tool kit for manipulation of genes from gram-negative bacteria. Appl Environ Microbiol. 2006;72:5027-36.

53. Chen DC, Beckerich JM, Gaillardin C. One-step transformation of the dimorphic yeast Yarrowia lipolytica. Appl Microbiol Biotechnol. 1997:48:232-5.

\section{Submit your next manuscript to BioMed Central and we will help you at every step:}

- We accept pre-submission inquiries

- Our selector tool helps you to find the most relevant journal

- We provide round the clock customer support

- Convenient online submission

- Thorough peer review

- Inclusion in PubMed and all major indexing services

- Maximum visibility for your research

Submit your manuscript at www.biomedcentral.com/submit
() Biomed Central 